\title{
Importance of public health tools in emerging infectious diseases
}

\author{
Jin-Ling Tang and Li-Ming Li argue that despite the lure of vaccines and new drugs, established \\ public health measures will remain our best tool to control covid-19 and future epidemics
}

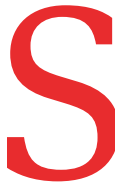

cientific advance occurs as the result of a passion for and continuing creation of new ideas, novel methods, and innovative technologies. This passion has made science the most successful of human endeavours and also made us tend to believe that new is better.

During the covid-19 pandemic, faith in new technologies affected our thinking about conventional tools. As Bruce Aylward, assistant director general of the World Health Organization, said at the beginning of the pandemic: "In the world of preparedness and planning, I suffer the same biases as, or maybe error of thinking as, many people. We don't have a vaccine; we don't have a therapeutic. And you hear it repeatedly in the news: people throwing up their hands." ${ }^{1}$ However, China's epidemic was effectively contained by using long established public health methods.

\section{Conventional public health measures in the pandemic}

In an epidemic caused by a new pathogen such as SARS-CoV-2 drugs and vaccines will not be immediately available. The only tools available to control the spread of disease are the public health measures that have been used for hundreds of years. These methods include, broadly speaking,

\section{REY MESSAGES}

- Over the past century, science has made medicine a great success and shaped a culture that new is better

- By rapidly mobilising old public health measures, China successfully contained its covid-19 epidemic

- Public health measures enhanced by new technologies can effectively contain or even eradicate new communicable diseases

- Healthcare needs appropriate technologies rather newer, advanced ones and new tests and drugs should be rigorously evaluated before they are introduced into practice controlling infection sources, blocking transmission routes, and protecting susceptible populations. Their effectiveness has been shown by the fact that infectious disease had been largely controlled by the middle of the 20th century, before antibiotics and vaccines became widely used. ${ }^{2}$

During the covid-19 pandemic, public health measures (now often called nonpharmacological interventions) have included mask wearing; identifying and quarantining infected people or close contacts; hand washing; social distancing, including closure of schools, entertainment venues, and public places; cancellation of public events; and restriction of travel. ${ }^{3}$ Nucleic acid testing and digital technologies meant public health measures could be mobilised fast, precisely, and efficiently.

The national campaign against the covid-19 epidemic in China started on 20 January 2020. Covid-19 was made a class B notifiable infectious disease (like measles and poliomyelitis) and responded to as a class A disease (like plague and cholera), with institution of substantial public health measures. Wuhan, the central epidemic area and a city of 11 million people, was locked down and put under quarantine on 23 January 2020. ${ }^{4}$ The entire country was subsequently brought into public health emergency response measures. The Wuhan lockdown was not a single measure but included multiple, rigorous public health and hygiene measures. ${ }^{34}$

The effectiveness of these measures is seen by the stabilisation and then decline in the daily number of cases a few days after they were implemented (fig 1). The delay in the effect is because of the incubation period of the virus, which is around six days. People infected before the national campaign on 20 January continued to infect others in the following six days, pushing the peak to 26 January. After that the daily number of new cases started to decline and continued so that there were virtually no cases by the end of March 2020.

How effective were these early actions? An early modelling study in the Lancet predicted that if the transmissibility of the virus and the mobility of people were not interrupted, the epidemic in Wuhan would peak around late April 2020 with some 30000 new cases daily. ${ }^{5}$ The epidemic in Wuhan actually peaked on 2 February 2020 , with 1967 new cases reported that day. This suggests that public health efforts after the Wuhan lockdown suppressed the peak number of daily new cases by over $93 \%$ and also ended the entire epidemic around two months earlier than predicted. ${ }^{5}$ Later modelling studies showed the interventions had prevented around $95 \%$ of infections. ${ }^{67}$ The travel restriction in Wuhan might have also reduced the number of cases outside China before March 2020 by $80 \%{ }^{8}$

Since April 2020, China has experienced 15 small outbreaks of covid-19, mostly imported, and it has shown repeatedly that these could be controlled with public health measures.

\section{More evidence for public health measures}

Public health measures have not been implemented so rigorously in all countries because of differences in culture and prevention strategies. Mask wearing, for example, is a common practice in China but highly debated in some other countries despite evidence of its effectiveness. ${ }^{910}$ As might be expected, the scale of the epidemic is largely proportionate to the rigorousness of public health measures in a country. For example, the epidemic has been mostly controlled to a small scale in Japan, Korea, and Singapore, where relatively rigorous public health measures were applied, whereas it has caused tens of millions infections and hundreds of thousands deaths in the UK and US, which were more reluctant to restrict people's behaviour.

The effect of public health measures on the epidemic can also be seen in places where the strength of these measures fluctuated over time. For example, in Hong Kong the epidemic closely followed the rhythms of the ups and downs of preventive measures in the city (fig 2). ${ }^{11}$ When public health measures were relaxed, the epidemic started to rise; conversely when they were 


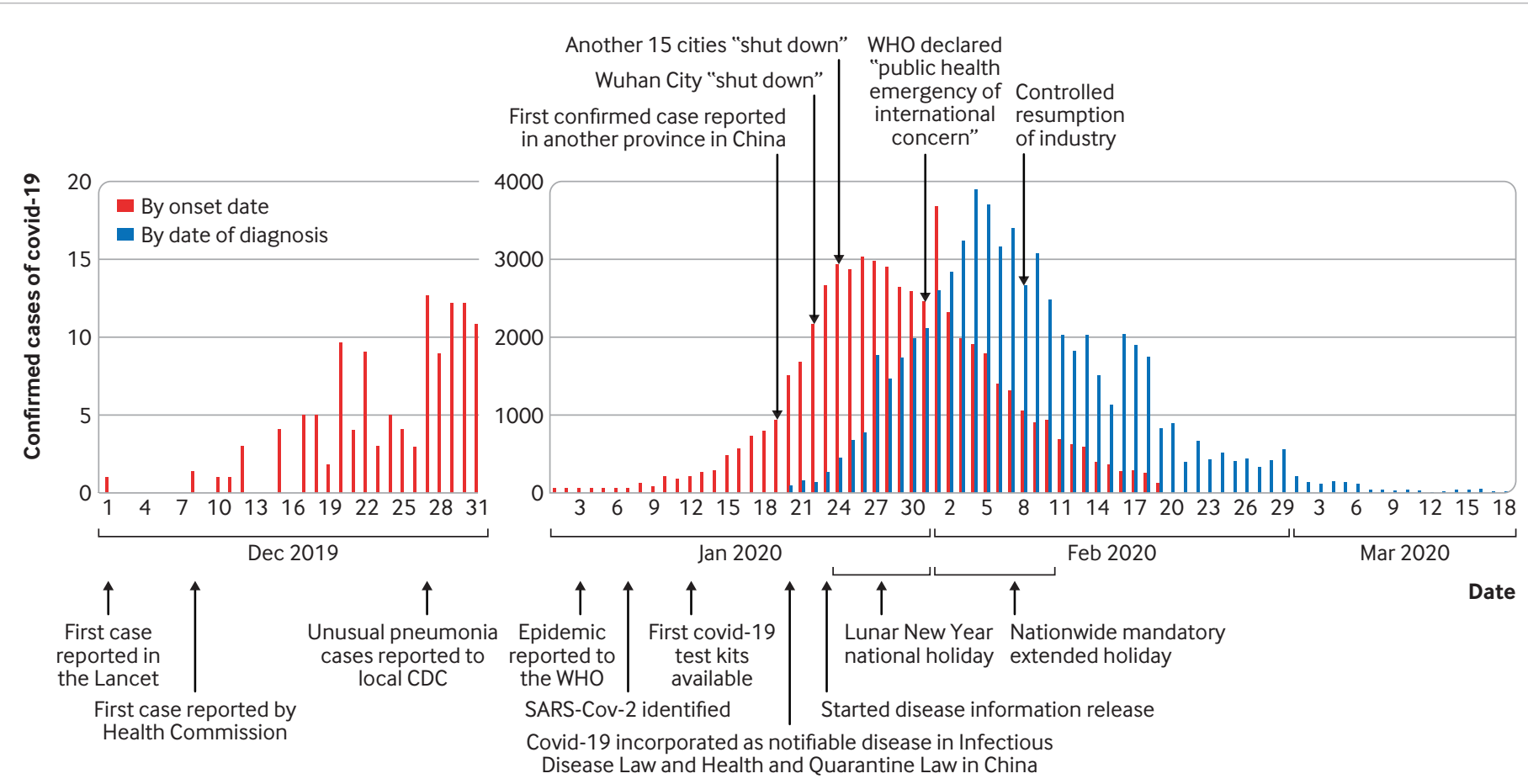

Fig 1 | Number of confirmed cases of covid-19 in China by date of onset and date of diagnosis (or reporting) with time points of major related events (adapted from Liang et $\mathrm{al}^{3}$ )

tightened, the epidemic started to decline. Studies have also showed that covid-19 control measures greatly reduced severe cases and deaths from other respiratory tract infections. ${ }^{12-14}$

Some may argue that the evidence is only observational and should be interpreted with caution. However, in situations such as the covid-19 epidemic that would have large scale, catastrophic consequences if not quickly and effectively controlled, we believe it is better to over-react than to be overcautious if the actions are affordable and have no obvious harms. Decisions should also be based on the best evidence available rather than best evidence theoretically possible.

\section{Contributions of new technologies}

New technologies also contributed to control of covid-19. For example, nucleic acid testing has made it possible to diagnose the disease early and detect people with asymptomatic infections so that secondary infections can be further reduced. Testing has also been used to optimise the length of hospital stay and to manage travel, reducing the personal inconvenience and economic interference caused by the epidemic. Mass testing has been used to assess the potential risk of a population.

Digital technologies have also helped. For example, the internet has been used to facilitate reporting of cases so that decision makers can quickly assess and adjust policies; computers have been used to model the features and development of the epidemic to inform policies; and mobile phones have been used to trace and manage close contacts and to contact and consult doctors to minimise hospital visits.

However, new technologies are only supportive. Public health methods would still work without them, although they would not be so quick, precise, or efficient. Importantly, China's experiences show that conventional methods enhanced by new technologies can eradicate an epidemic of new infectious disease in its early stages in the absence of effective drugs and vaccines.

Conventional methods also provided time for the development of vaccines.

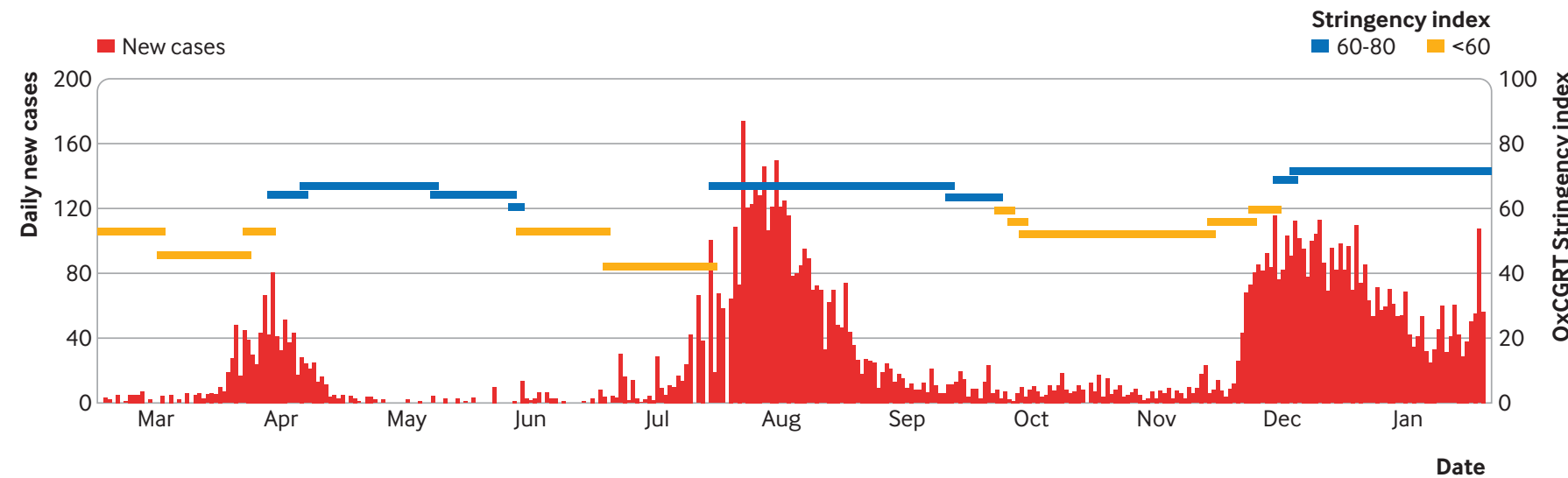

Fig 2 | Daily new cases of covid-19 in Hong Kong from 15 February 2020 to 20 January 2021 and stringency of public health measures assessed by Oxford covid-19 government response index 
Vaccines have now become the determining factor in whether we can eventually control the pandemic. However, it is unlikely that vaccines alone can end the pandemic. This is because vaccines are not $100 \%$ effective and breakthrough infections exist; the protection from vaccines may not last long enough; and vaccines may not be effective against new variants. Public health measures remain the manoeuvrable factors.

\section{New does not mean better}

In response to emergencies like the covid19 epidemic, the belief that new is better may make us distrust and indecisive about conventional technologies. China's experiences show clearly that conventional methods remain appropriate and powerful in such situations.

On the other hand, the belief that new is better has created a flood of new diagnostic and therapeutic technologies in medicine. They include technologies for detecting small cancers, those for measuring the same clinical conditions differently, new biomarkers and artificial intelligence for predicting prognosis and guiding treatment, minimally invasive methods for surgical operations, new drugs, and so on.

How often are the newer not better than the older? Table 1 shows examples in which newer technologies are no better or even worse than older or current standard treatments. A recent German study found that more than half of new drugs entering the German healthcare system had not been shown to add benefit. ${ }^{21}$ More recently, a $B M J$ article reported that since the US Food and Drug Administration established its accelerated approval pathway for drugs in 1992, nearly half (112) of the 253 drugs authorised have not been confirmed as clinically effective and a fifth (24) have been on the market for more than five years and some for more than two decades. ${ }^{22}$

New technologies are often developed for early diagnosis with a belief that early diagnosis brings about greater benefits. However, it may take years or even decades to find out whether an early diagnostic method is truly beneficial to patients. This creates a large chance for ineffective technologies to sneak into medical practice and be widely used for years or even decades. Molecular diagnostics have been expanding rapidly yet many have not been proved clinically useful, partly because of regulatory failings. ${ }^{23}$

Take prostate cancer screening as an example. Before the 1980s, most solid cancers could be diagnosed only by symptoms, signs, and imaging. The discovery of prostate specific antigen (PSA) in 1971 was considered an exciting breakthrough and caused great enthusiasm for screening for prostate cancer. PSA testing was introduced in the late 1980 s as a safe, quick, simple, and inexpensive method. In 1994, the US Food and Drug Administration approved the use of PSA testing in conjunction with digital rectal examination to test asymptomatic men for prostate cancer. By the early 2000 s, around $75 \%$ of men aged 50 years or older had had PSA testing and $90 \%$ of prostate cancers were detected by screening in the US. However, after 13 years' follow-up, a randomised controlled trial of 76685 men showed no evidence of a mortality benefit from PSA screening. ${ }^{24}$
Prostate cancer screening is not a rare case. A systematic review of meta-analyses and trials of 39 tests for screening for 19 diseases or disorders found that reductions in disease specific mortality are uncommon and reductions in all-cause mortality are rare. $^{25}$

\section{Focus on appropriate tools}

Science has made medicine much more powerful and effective and will continue to create new technologies, advance medicine, and benefit health. However, our faith in innovation should not prevent us from necessary use of appropriate conventional technologies, particularly in emergencies.

Faced with a similar epidemic in the future, traditional public health methods should be deployed as a first response since vaccines will not be immediately available. Public health measures enhanced by new technologies can eradicate such an epidemic even in the absence of a vaccine. Discounting conventional wisdom and over-promising for new technologies in such emergencies may result in disastrous consequences. Even outside epidemics, new tests and drugs should be rigorously evaluated before they are introduced into routine practice to ensure they truly benefit patients.

We thank Dayi Hu, Chen Mao, Zuyao Yang, and Lizheng Shi for suggesting the examples on comparisons between new and old technologies, and Ziyi Zhao for helping with the references and table. JLT is supported partly by Shenzhen Science and Technology Program (Grant Nos KQTD20190929172835662 and RKX20210901150004012). LMI is partly supported by the grants of Peking University (PKU2020PKYZX002) and the China Medical Board (20-366).

Contributors and sources: JLT proposed the topic and drafted a manuscript. LLM exchanged ideas

\begin{tabular}{|c|c|c|c|c|c|}
\hline Trial & Clinical condition & New treatment & Comparison treatment & Outcome events & Conclusions \\
\hline Chimowitz et al ${ }^{17}$ & $\begin{array}{l}\text { Intracranial arterial } \\
\text { stenosis }\end{array}$ & $\begin{array}{l}\text { Percutaneous } \\
\text { transluminal angioplasty } \\
\text { and stenting }\end{array}$ & $\begin{array}{l}\text { Aggressive medical } \\
\text { therapy }\end{array}$ & Stroke or death at 30 days & $\begin{array}{l}\text { Aggressive medical therapy was better than } \\
\text { percutaneous transluminal angioplasty and } \\
\text { stenting }\end{array}$ \\
\hline El-Hayek et al ${ }^{18}$ & $\begin{array}{l}\text { Coronary artery } \\
\text { disease }\end{array}$ & $\begin{array}{l}\text { Biodegradable polymer } \\
\text { drug eluting stents }\end{array}$ & $\begin{array}{l}\text { Second generation } \\
\text { durable polymer drug } \\
\text { eluting stents }\end{array}$ & $\begin{array}{l}\text { Revascularisation, cardiac } \\
\text { death, myocardial infarction, } \\
\text { definite or probable stent } \\
\text { thrombosis at } 26 \text { months }\end{array}$ & $\begin{array}{l}\text { Biodegradable stents have similar safety } \\
\text { and efficacy profiles to second generation } \\
\text { stents }\end{array}$ \\
\hline Gaudino et al $^{19}$ & $\begin{array}{l}\text { Coronary artery } \\
\text { disease }\end{array}$ & $\begin{array}{l}\text { Percutaneous coronary } \\
\text { intervention (PCI) }\end{array}$ & $\begin{array}{l}\text { Coronary artery bypass } \\
\text { grafting (CABG) }\end{array}$ & $\begin{array}{l}\text { Total and cardiac deaths at } 5 \\
\text { years }\end{array}$ & $\begin{array}{l}\text { PCI was associated with higher all-cause, } \\
\text { cardiac, and non-cardiac mortality than } \\
\text { CABG }\end{array}$ \\
\hline
\end{tabular}


and revised the manuscript. Both approved the final version. JLT is the guarantor.

Competing interests: All authors have read and understood BMJ policy on declaration of interests and have no interests to declare. JLT is a clinical research editor for The BMJ.

Provenance and peer review: Commissioned; externally peer reviewed.

This article is part of a collection proposed by the Peking University Center for Public Health and Epidemic Preparedness and Response. Open access fees were funded by individual institutions. The $B M J$ commissioned, peer reviewed, edited, and made the decision to publish. Li-Ming Li advised on commissioning for this collection. Jin-Ling Tang, Di Wang, and Kamran Abbasi were the lead editors for The BMJ.

Jin-Ling Tang, professor ${ }^{1,2}$

Li-Ming Li, professor ${ }^{3}$

${ }^{1}$ Shenzhen Institute of Advanced Technology of the Chinese Academy of Sciences, Shenzhen, China

${ }^{2}$ Guangzhou Women and Children's Medical Centre, Guangzhou, Guangdong Province, China

${ }^{3}$ School of Public Health, Peking University, Beijing, China Correspondence to: J-LTang jltang@cuhk.edu.hk

\section{(c) (1) \& OPEN ACCESS}

This is an Open Access article distributed in accordance with the Creative Commons Attribution Non Commercial (CC BY-NC 4.0) license, which permits others to distribute, remix, adapt, build upon this work non-commercially, and license their derivative works on different terms, provided the original work is properly cited and the use is non-commercial. See: http://creativecommons.org/licenses/by-nc/4.0/.

\section{D) Check for updates}

1 World Health Organization. Press conference of WHOChina joint mission on covid-19. 24 Feb 2020. https:// www.who.int/docs/default-source/coronaviruse/ transcripts/joint-mission-press-conference-scriptenglish-final.pdf?sfvrsn=51c90b9e_10

2 Mckeown T. The role of medicine: dream, mirage, or nemesis? Princeton University Press, 1979.

3 Liang H, Zheng L, Xia H, Tang J. SARS-CoV-2 infection in China before the pandemic. PLoS Negl Trop Dis 2020:14:e0008472. doi:10.1371/journal. pntd. 0008472

4 Pan A, Liu L, Wang C, et al. Association of public health interventions with the epidemiology of the covid-19 outbreak in Wuhan, China. JAMA 2020;323:1915-23. doi:10.1001/jama.2020.6130

5 Wu JT, Leung K, Leung GM. Nowcasting and forecasting the potential domestic and international spread of the 2019-nCoV outbreak originating in Wuhan, China: a modelling study. Lancet 2020;395:689-97. doi:10.1016/S01406736(20)30260-9

6 Lai S, Ruktanonchai NW, Zhou L, et al. Effect of nonpharmaceutical interventions to contain COVID-19 in China. Nature 2020;585:410-3. doi:10.1038/ s41586-020-2293-x

7 Wang C, Liu L, Hao X, et al. Evolving epidemiology and impact of non-pharmaceutical interventions on the outbreak of coronavirus disease 2019 in Wuhan, China.medRxiv 2020:20030593 [Preprint]. doi:10.1 101/2020.03.03.20030593.

8 Chinazzi M, Davis JT, Ajelli M, et al. The effect of travel restrictions on the spread of the 2019 novel coronavirus (covid-19) outbreak. Science 2020;368:395-400. doi:10.1126/science.aba9757

9 Chou R, Dana T, Jungbauer R, Weeks C, McDonagh MS. Masks for prevention of respiratory virus infections, including SARS-CoV-2, in health care and community settings: a living rapid review. Ann Intern Med 2020;173:542-55. doi:10.7326/M20-3213

10 Chu DK, Akl EA, Duda S, Solo K, Yaacoub S, Schünemann HJ, COVID-19 Systematic Urgent Review Group Effort (SURGE) study authors. Physical distancing, face masks, and eye protection to prevent person-to-person transmission of SARS-CoV-2 and COVID-19: a systematic review and meta-analysis. Lancet 2020;395:1973-87.10.1016/S01406736(20)31142-9

11 Zhang RN, Liang ZR, Pang MF, et al. Mobility trends and effects on the covid-19 epidemic-Hong Kong, China. China CDC Weekly 2021;3:159-61. doi:10.46234/ccdcw2021.020.

12 Hatoun I, Correa ET, Donahue SMA, Vernacchio L. Social distancing for COVID-19 and diagnoses of other infectious diseases in children. Pediatrics 2020:146:e2020006460 doi:10.1542/ peds.2020-006460

13 Kuitunen I, Artama M, Mäkelä L, Backman K, HeiskanenKosma T, Renko M. Effect of social distancing due to the COVID-19 pandemic on the incidence of viral respiratory tract infections in children in Finland during early 2020. Pediatr Infect Dis / 2020;39:e423-7. doi:10.1097/ INF.0000000000002845

14 Lin CF, Huang YH, Cheng CY, Wu KH, Tang KS, Chiu IM. Public health interventions for the COVID-19 pandemic reduces respiratory tract infection-related visits at pediatric emergency departments in Taiwan. Front Public Health 2020;8:604089. doi:10.3389/ fpubh. 2020.604089

15 Ramirez PT, Frumovitz M, Pareja R, et al. Minimally invasive versus abdominal radical hysterectomy for cervical cancer. N Engl / Med 2018:379:1895-904. doi:10.1056/NEJMoa1806395

16 Patel R, Powell JT, Sweeting MJ, Epstein DM, Barrett JK, Greenhalgh RM. The UK EndoVascular Aneurysm Repair (EVAR) randomised controlled trials: long-term follow-up and cost-effectiveness analysis. Health Technol Assess 2018;22:1-132. doi:10.3310 hta22050

17 Chimowitz MI, Lynn MJ, Derdeyn CP, et al, SAMMPRIS Trial Investigators. Stenting versus aggressive medical therapy for intracranial arterial stenosis. N Engl J Med 2011;365:993-1003. doi:10.1056/ NEJMoa1105335

18 El-Hayek G, Bangalore S, Casso Dominguez A, et al. Meta-analysis of randomized clinical trials comparing biodegradable polymer drug-eluting stent to secondgeneration durable polymer drug-eluting stents. JACC Cardiovasc Interv 2017;10:462-73. doi:10.1016/j. jcin.2016.12.002

19 Gaudino M, Hameed I, Farkouh ME, et al. Overall and cause-specific mortality in randomized clinical trials comparing percutaneous interventions with coronary bypass surgery: a meta-analysis. JAMA Intern Med 2020;180:1638-46. doi:10.1001/ jamainternmed.2020.4748

20 ALLHAT Officers and Coordinators for the ALLHAT Collaborative Research Group. Major outcomes in high-risk hypertensive patients randomized to angiotensin-converting enzyme inhibitor or calcium channel blocker vs diuretic: the Antihypertensive and Lipid-Lowering Treatment to Prevent Heart Attack Trial (ALLHAT). JAMA 2002;288:2981-97. doi:10.1001/jama.288.23.2981

21 Wieseler B, McGauran N, Kaiser T. New drugs: where did we go wrong and what can we do better? BMI 2019:366:14340, doi:10.1136/bmj.14340

22 Mahase E. FDA allows drugs without proven clinical benefit to languish for years on accelerated pathway. BMJ 2021:374:n1898. doi:10.1136/bmi.n1898

23 Holloway K, Miller FA, Gutierrez A, Hogarth S Dangerous diagnostics? Regulatory reform in the genomic era. BMJ 2019;364:1640. doi:10.1136/ bmj.1640

24 Andriole GL, Crawford ED, Grubb RL3rd, et al, PLCO Project Team. Prostate cancer screening in the randomized prostate, lung, colorectal, and ovarian cancer screening trial: mortality results after 13 years of follow-up. J Natl Cancer Inst 2012;104:125-32. doi:10.1093/jnci/djr500

25 Saquib N, Saquib J, loannidis JPA. Does screening for disease save lives in asymptomatic adults? Systematic review of meta-analyses and randomized trials. Int J Epidemiol 2015;44:264-77. doi:10.1093/ije/dyu140

Cite this as: $B M / 2021 ; 375: \mathrm{n} 2374$

http://dx.doi.org/10.1136/bmj.n2374 